\title{
Driving under the influence of drugs in Italy: Describing two assessment protocols
}

\author{
Arianna Pioda ${ }^{1}$, Isabella Mercurio ${ }^{1}$, Giovanni Battista Pioda ${ }^{2}$, Mauro Bacci ${ }^{1}$, Gianmarco Troiano ${ }^{3}$ \\ and Cristiana Gambelunghe ${ }^{1, *}$ \\ ${ }^{1}$ Department of Medicine and Surgery, Forensic and Sports Medicine Section, University of Perugia, \\ Piazza Lucio Severi, 06132 Sant'Andrea delle Fratte, Perugia; ${ }^{2}$ Health Service of the Italian State, \\ Police Headquarters of Bologna,Via Bovi Campeggi 13, 40122 Bologna; \\ ${ }^{3}$ University of Siena, Via Aldo Moro, 53100 Siena, Italy.
}

\begin{abstract}
Although penalties for violating Italy's laws on driving under the influence of drugs (DUID) are very strict, no national protocol is enforced in order to assess possible offences in traffic accidents and routine traffic patrols. We describe two protocols that were applied to assess 298 cases of potentially impaired drivers out of 1653 stopped in Perugia, a town in Central Italy. One protocol was the D.O.S. carried out by means of oral fluid and urine and blood for confirmatory analysis. The other "SALIVA" uses only oral fluid collected during the road checkpoints. Psychoactive drugs were present in about $30 \%$ of the suspected drivers under both protocols, with cannabis being most often detected. The number of drivers who were sanctioned for DUID was significantly higher under the SALIVA protocol. Because non-standardized procedures showed critical issues, it is necessary to harmonize DUID national protocols. Toxicological screening and confirmatory tests, with standard analytic procedures, should be developed.
\end{abstract}

KEYWORDS: driving under the influence of drugs, oral fluid analysis, blood analysis, drug abuse, on-site drug tests, forensic toxicology.

\section{ABBREVIATIONS}

World Health Organization (WHO)

*Corresponding author: cristiana.gambelunghe@unipg.it
Driving under the influence of drugs (DUID)

DRUGS ON STREET (D.O.S.)

Gas chromatography/mass spectrometry (GC/MS)

Italian Group of the Forensic Toxicologists (GTFI)

Amphetamine (AMP)

Benzodiazepines (BZDs)

Cocaine (COC)

Methadone (Met)

Methamphetamine (MAMP)

Opiates (OPI)

Delta-9-Tetrahydrocannabinol (THC)

Positive Predictive Value (PPV)

Blood Alcohol Concentration (BAC)

\section{INTRODUCTION}

Road accidents are a major concern in terms of citizens' safety, wellbeing and actual health, and, as they are constantly increasing, they are a major cause of morbidity and mortality for young adults. Every year, about 1.2 million people worldwide are involved in fatal accidents with more than 50 million people being injured, as a result. As a matter of fact, the World Health Organization (WHO) has predicted a $65 \%$ increase in mortality and injury rates by 2020 [1]. Driving under the influence of drugs (DUID), contributes directly or indirectly to a high percentage of road accidents in developed and developing countries alike [2].

Multiple drug use and drug combination with alcohol are quite common among DUID offenders. Since they constitute a considerable threat to traffic safety, some European countries have introduced "zero tolerance" 
legislations for driving under the influence of drugs, whereas other countries have established impairing thresholds for drugs in blood and saliva [2, 3]. Reducing the number of people driving under the influence of alcohol and/or drugs is a long-term goal and both researchers and law enforcement agencies have emphasized the need for officers on road patrolling duty to administer advanced onsite drug tests directly at the roadside check point or in a police station [4]. In the last decade, in most European DUID cases, urine sampling was the preferred way to carry out on-site drug pretesting, as it reduced the number of unnecessary blood tests [5]. For this reason, it is still used in Italy, but the results of urine pre-tests and/or confirmatory follow-on tests cannot be used as evidence of the actual extent of driving impairment, because drugs and/or their metabolites are detected in urine for days or even weeks after the last intake [6,7]. Blood provides the most reliable information on a subject's state of intoxication, (immediately before or during driving), because it provides relatively sound evidence of impairment and, as such, it is admitted as evidence in court [8]. This is, however, the most invasive procedure and individuals must be transported to a healthcare facility to collect the sample [8]. On the other hand, oral fluid testing of drivers in traffic safety enforcement procedures is currently routinely carried out in several countries including Australia, Germany, Belgium, Spain, the United Kingdom, while the procedure is under evaluation in other countries $[9,10]$. The first onsite tests to ascertain the presence of drugs in oral fluid were developed during the 1990s [11]. A non-invasive roadside screening method, i.e. oral fluid testing enables direct supervision of sampling $[12,13]$. One of its strengths is that positive findings are expected to provide sounder evidence of impairment than the outcome of tests on urine samples [11, 14]. Several studies showed good correlations with the presence or absence of drugs in oral fluid, blood and systemic symptoms [11, $15,16]$. However, different studies underlined that reliable evidence of the connection between drugs concentration and impairment can only be based on blood concentrations. In fact, oral fluid concentrations are elevated shortly after drug-use, since drugs generally appear in the oral fluid by passive diffusion from blood. Additionally, drugs may be also deposited during oral and intranasal administration and through smoking [17-19].
Legislation on the use of alcohol and drugs while driving varies from country to country [20] as does the legal definition of a driver under the influence of alcohol and/or drugs [21]. In Italy, Artt.n. 186 and n. 187 [22], respectively, of the National Highway Code and its recent update Road Traffic Law n. 41, 2016 [23] regulate driving under the influence of alcohol and drugs. The said provisions prohibit drunk driving with a ceiling of three blood alcohol concentrations $(0.5 \mathrm{~g} / \mathrm{L}, 0.8 \mathrm{~g} / \mathrm{L}$ and $1.5 \mathrm{~g} / \mathrm{L})$ for graded fines and sanctions. As for driving "in a state of psychophysical alteration", due to an intake of narcotics and psychotropic substances, no thresholds have been established up to now. Consequently, the presence of any illicit drug in a driver's blood sample is a severe violation of the law that is punished with penal sanctions [7]. Despite this zero-tolerance approach to DUID in the Italian legislation, no protocol enforced nationwide is extant that assesses DUID offences in traffic accidents and in routine traffic checks.

As an example of lack of harmonization of DUID assessment in Italy, herewith we illustrate two protocols for roadside drug testing in Perugia, a town of nearly 166,000 inhabitants in Central Italy. Municipal Police DRUGS ON STREET (D.O.S.) protocol is implemented at specific checkpoints on city streets, during night hours, on weekends, by means of oral fluid, urine and blood sampling. The Traffic Police SALIVA protocol was carried out on country roads near large discos on weekends, and it uses only oral fluid sampling. 298/1653 drivers were asked to pull over and tested for drugs under two protocols. The present study describes data from both experimental roadside protocols and highlights the different characteristics of the biological matrices used and the critical aspects that each protocol presents.

\section{MATERIALS AND METHODS}

Data sources were the Municipal Police of Perugia for the D.O.S. protocol and the Perugia section of the Traffic Police for the SALIVA protocol. Under both protocols, drivers were randomly asked to pull over and checked at specially set-up checkpoints. Police officers suspected that the driver was impaired when inappropriate driving behavior, (speeding, irregular driving direction change, and abnormal speed control) and/or psycho-physical disturbances (e.g. motor coordination, sleepiness, 
mood/behavior smell of alcohol, markedly dilated or constricted pupils with no or only weak reactions to light), were observed according to the same specific protocol to test physical impairment applied by both Municipal Police and Traffic Police. All drivers that, for these reasons, were suspected of being in a state of psychophysical alteration, were tested for alcohol and drugs. Under both protocols, a refusal to take the breathalyzer test and/or drugs test implied that maximum penalties would be applied.

Drug analyses were carried out by an initial screening test based on immunoassay technology; all positive screening results were confirmed by gas chromatography/mass spectrometry (GC/MS). The panel of drugs and the related cut-offs of the GC/MS analysis are reported below, for each protocol, in the 'confirmatory testing' section.

\section{D.O.S. protocol on urban streets}

The D.O.S. project, which is coordinated nationwide by the Italian Department of Anti-Drug Policies, is implemented in 50 Italian cities. In Perugia it was conducted on 738 drivers randomly stopped, over a two-year period (July 2012-July 2014), by the Municipal Police during 20 specific weekend night shifts (12 a.m. - 7 a.m. on Friday and Saturday nights). Checkpoints were set up on urban roads in the Municipality of Perugia, close to entertainment venues, and were equipped with a medical camper or an ambulance.

For all drivers who were suspected of psychophysical alteration the D.O.S. protocol included:

1) Breath test for alcohol ("ALCOBLOW R ZERO" for preliminary test and "DRAGER WERK alcoltest 7110 MKIII" to confirm positive result).

2) Oral fluid test for drugs: a screening test carried out with a "DDS2 Mobile Test System" (Alere Toxicology, Abbot, Italy) European Conformity marked (Medical Device Directive (93/42/EEC and 98/79/EC), validated for analyzing 6 classes of substances with the following cut-offs: amphetamine (AMP) $50 \mathrm{ng} / \mathrm{ml}$, benzodiazepines (BZDs) $20 \mathrm{ng} / \mathrm{ml}$, cocaine (COC) $30 \mathrm{ng} / \mathrm{ml}$, methadone (Met) $15 \mathrm{ng} / \mathrm{ml}$, methamphetamine (MAMP) and MDMA $50 \mathrm{ng} / \mathrm{ml}$, opiates (OPI) 40 $\mathrm{ng} / \mathrm{ml}$, Delta-9-Tetrahydrocannabinol (THC) $25 \mathrm{ng} / \mathrm{ml}$.
3) Urine test as screening test performed with "DDS Urine Test Kits" device (screening test), on 5 classes of substances with the following cut-offs: AMP $1000 \mathrm{ng} / \mathrm{ml}$, MAMP and MDMA $500 \mathrm{ng} / \mathrm{ml}$, COC $300 \mathrm{ng} / \mathrm{ml}$, OPI 300 $\mathrm{ng} / \mathrm{ml}$, THC $50 \mathrm{ng} / \mathrm{ml}$.

4) Confirmatory testing: All drivers, who tested positive in oral fluid and/or urine screening, were escorted by a police officer to the emergency room in Perugia General Hospital to give a blood sample. It was divided into three aliquots, under a chain of custody, and then analyzed by GC/MS with the following cut-offs: AMP $2 \mathrm{ng} / \mathrm{ml}$, MAMP and MDMA $2 \mathrm{ng} / \mathrm{ml}$, COC $2 \mathrm{ng} / \mathrm{ml}$, OPI $2 \mathrm{ng} / \mathrm{ml}$, THC $1 \mathrm{ng} / \mathrm{ml}$, as established by the Guidelines of the Italian Group of the Forensic Toxicologists (GTFI) that indicate limits to be used in this type of analysis [24].

\section{SALIVA protocol on country roads}

The SALIVA protocol (October 2014-October 2016) was implemented by the Perugia Section of the Traffic Police. In a two-year period (October 2014-October 2016), the local Traffic Police personnel checked 915 drivers in 21 specific weekend night shifts on country roads near large discos, in areas where drugs' pushing and drug use was known to occur. All drivers who were suspected of psychophysical alteration underwent:

1) Breath test for alcohol ("ALCOBLOW R ZERO" for primary test and "DRAGER WERK alcohol test 7110 MKIII" to confirm positive result).

2) Oral fluid test for drugs with "Drager Drug Test 5000 " analyzer equipment with the same drug classes and cut-offs as the D.O.S. protocol.

3) Confirmatory testing: In cases of positivity to the screening test, three aliquots of oral fluid were collected and stored in refrigerated unit $\left(4{ }^{\circ} \mathrm{C}\right)$ under chain of custody. Two such samples were sent to the Police Laboratory Research Center and Forensic Toxicology in Rome for confirmatory analysis in GC/MS with the following cut-offs: AMP $15 \mathrm{ng} / \mathrm{ml}$, MAMP and MDMA $15 \mathrm{ng} / \mathrm{ml}$, COC $8 \mathrm{ng} / \mathrm{ml}$, OPI $15 \mathrm{ng} / \mathrm{ml}$, THC $2 \mathrm{ng} / \mathrm{ml}$, as established by GTFI as minimum reporting limits [24]. 


\section{Statistical analysis}

Data were inserted into a database and processed using the software package Stata ${ }^{\circledR} \mathrm{SE}$, version 12.1 (StataCorp, College Station, Texas, USA). Percentages, means and standard deviations were extrapolated, and descriptive charts and tables were drawn up. The $\chi^{2}$ test and Odds Ratio along with logistic regression were performed to identify significant differences in the two groups $(p<0.05)$; multiple regression was used to identify significant differences in each protocol using alcohol positivity as dependent variable. With the available data (as at the screening tests negative samples were eliminated from further investigations), we calculated, for both protocols, the Positive Predictive Value (PPV). The said PPV could be defined as the percentage of subjects with a positive test screening ascertained by means of confirmatory analysis. It is calculated using the following formula: $\% \mathrm{PPV}$ $=\mathrm{a} / \mathrm{a}+\mathrm{b}=\mathrm{a}$ (true positive) $/ \mathrm{a}+\mathrm{b}$ (true positive + false positive) $\times 100$.

\section{RESULTS}

Table 1 reports the details of those suspected of driving under the influence of alcohol and drugs that were tested under the D.O.S. and SALIVA protocols.

\section{D.O.S. protocol}

Municipal police officers suspected 94/738 drivers, $(12.74 \%)$ of drunk driving and driving under the influence of drugs by observing their driving behavior and symptoms of suspected impairment.
The sample revealed a predominance of male drivers $(84.04 \%)$ who were mainly over 30 years of age $(80.85 \%)$. 62/94 $(65.96 \%)$ tested positive for alcohol and 29/94 (30.85\%) for drugs on the screening test. Confirmatory analyses were carried out only on 20 drivers at the hospital, since 9 of them refused to confirm screening test results. All 20 also proved positive to alcohol and exceeded the Blood Alcohol Concentration (BAC) BAC limit of $0.5 \mathrm{~g} / \mathrm{L}$. Blood analysis by GC/MS confirmed drug positivity in 10 cases out of 20 , with a clear prevalence of THC (6 THC, 2 COC, 2 AMP). $5 / 10$ positive cases in the screening test were false positives as they did not contain any metabolites of suspected substances in blood; the other 5 samples contained metabolites in blood that were no longer pharmacologically active, so that DUID could not be ascertained.

Altogether, 19 drivers (2.5\%) were fined and subjected to sanctions for DUID, (10 for the confirmed presence of active drug in blood, and 9 on account of their refusal to undergo the drug test). Figure 1A shows the main results from D.O.S. protocol.

Those who were positive for THC also had a lower tendency to use cocaine $(p=0.04$; OR 0.18). A multiple logistic regression comparing the positivity to alcohol test versus all drugs (also considering age and sex as variables) was not statistically significant because of the limited number of positives.

\section{SALIVA protocol}

Out of 915 drivers who were checked, (over 22\%), traffic police officers suspected 204 drivers

Table 1. Main features of the D.O.S and SALIVA protocols.

\begin{tabular}{|l|c|c|c|c|c|}
\hline \multirow{2}{*}{ Drivers stopped } & \multicolumn{2}{|c|}{ Saliva protocol } & \multicolumn{2}{c|}{ D.O.S protocol } & \\
\cline { 2 - 6 } & Value & Percentage & Value & Percentage & P value \\
\hline Drivers suspected of DUID & 915 & - & 738 & - & - \\
\hline Males & 204 & $22.29 \%^{\mathrm{a}}$ & 94 & $12.74 \%^{\mathrm{a}}$ & - \\
\hline Females & 153 & $75.47 \% \mathbf{0}^{\mathrm{b}}$ & 79 & $84.04 \%^{\mathrm{b}}$ & - \\
\hline$>\mathbf{3 0}$ years & 51 & $24.53 \%^{\mathrm{b}}$ & 15 & $15.96 \%^{\mathrm{b}}$ & - \\
\hline$<\mathbf{3 0}$ years & 72 & $35.29 \%^{\mathrm{b}}$ & 76 & $80.85 \%^{\mathrm{b}}$ & $\mathbf{0 . 0 5}$ \\
\hline Alcohol positivity & 132 & $64.71 \%^{\mathrm{b}}$ & 18 & $14.95 \%^{\mathrm{b}}$ & $\mathbf{0 . 0 5}$ \\
\hline
\end{tabular}

${ }^{\mathrm{a}}$ Percentages of drivers suspected of DUID on the total of drivers stopped.

${ }^{\mathrm{b}}$ Percentages on drivers suspected of DUID. 

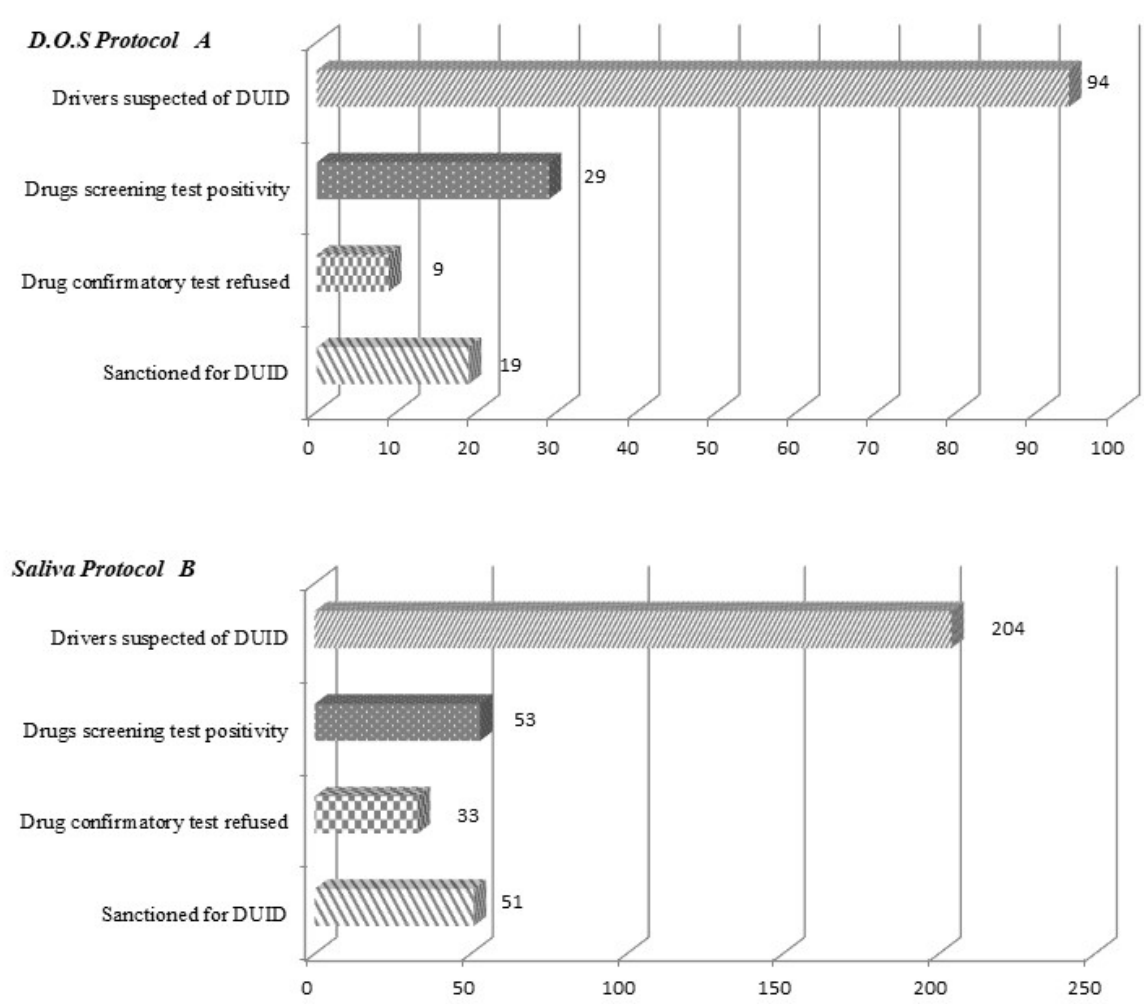

Figure 1. Outcome of D.O.S. Protocol (A) and SALIVA protocol (B).

of being in a state of psychophysical alteration. They underwent both drug and alcohol tests. The sample revealed a predominance of male drivers $(75.47 \%)$ who were mainly under 30 years of age. Moreover, 144/204 (70.59\%) tested positive for alcohol and 53/204 (25.98\%) for drugs after oral fluid screening. Polydrug use and combination with alcohol was present in $64 \%$ of samples. As 33/53 of the suspected drivers refused to confirm preliminary results, GC/MS confirmatory analyses were performed on 20/53 (37.74\%), establishing drug positivity in $18 / 20$ cases $(90 \%)$. 11/18 (61.1\%) were single positivity (7 THC, 3 COC, 1 AMP), 7/18 double positivity (3 THC+COC, $1 \mathrm{COC}+\mathrm{AMP}, 1 \mathrm{COC}+\mathrm{OP})$. In total 51 drivers $(96.23 \%)$ were sanctioned for DUID (18 for drug positivity and 33 for having refused to undergo the tests). Figure 1A shows the main results from the D.O.S. protocol.

The calculation of single Odds ratios by comparing the positivity to alcohol test versus each single drug highlighted significant results only for THC (OR 5.30, p 0.0064). A multiple logistic regression analysis comparing the positivity to alcohol test versus all drugs showed instead significant results:
- THC OR $62.44 \mathrm{p}<0.01$

- COC OR $6.43 \mathrm{p}=0.03$

- AMP OR $44.81 \mathrm{p}<0.01$

- OPI OR $34.01 \mathrm{p}=0.03$

However, if we considered also age and gender as variables in multiple regression model, we observed a slight difference from the above-mentioned results:

- THC OR $124.60 \mathrm{p}<0.01$

- COC OR $5.68 \mathrm{p}=0.09$ (not significant P-value)

- AMP OR $70.70 \mathrm{p}=0.01$

- OPI OR $28.49 \mathrm{p}=0.04$

- Age OR $0.89 \mathrm{p}=0.03$

- Gender (considering 1 as male, and 0 as female) OR $0.36 \mathrm{p}=0.31$

\section{Inter-Protocol analysis}

A significant age difference emerged $(\mathrm{p}=0.04)$, with a lower age in the SALIVA protocol. However a not significant difference was observed when the samples were analyzed based on 2 categories: drivers over 30 years of age and drivers under 30 years of age, respectively $(\mathrm{OR}=0.31, \mathrm{p}=0.05)$. No gender-related differences were observed $(\mathrm{p}>0.05)$. 
No significant differences emerged in alcohol test positivity $(p=0.66)$. People aged $>30$ years had a lower risk of testing positive to alcohol $(\mathrm{p}=0.01$, $\mathrm{OR}=0.22)$. The refusal-to-be-tested rate was significantly higher in the SALIVA protocol $(\mathrm{p}<$ 0.01 , OR 3.66). There was no significant difference in drug positivity (all $\mathrm{p}>0.05$ ).

The number of drivers who were sanctioned for DUID was significantly higher under the SALIVA protocol $(\mathrm{p}<0.01$, OR 13.42).

\section{DISCUSSION}

The present study illustrates two protocols that were implemented in the town of Perugia to identify drivers under the influence of alcohol (by means of breath tests) and drugs. The two protocols had the same purpose, i.e. to counter the phenomenon of driving under the influence of alcohol and drugs and were aimed at preventing the related alcohol and drug-related accidents due to drunk driving and driving under the influence of drugs. Despite having the same purpose, they were differently structured and carried out by different law enforcement agencies that operate in the territory. The D.O.S protocol provided checkpoints on urban streets for drug screening of oral fluid and urine, the results of which were then confirmed by GC/MS analysis of blood. The SALIVA protocol was performed on country roads near large discotheques, using only oral fluid for both screening and confirmatory analyses.

Despite the fact that the said impairment assessments were performed according to the same protocols endorsed by the Municipal and Traffic Police, the number of drivers suspected of being in a state of psychophysical alteration was higher in the tests based on the SALIVA protocol (22\%) with respect to the tests related to D.O.S (12.74\%). This could be partly explained by the fact that the SALIVA protocol was implemented in areas with numerous drug-intoxicated individuals. However, this could also be due to a different "yardstick" on suspected drug impairment as a result of the checks conducted by the two different law enforcement agencies.

Combining the results of both protocols, the majority of all 1653 drivers under consideration had used substances that could impair their driving performances (66-71\% were fined for drunk driving and $2.5-5.6 \%$ were fined on account of driving under the influence of drug). A significant difference emerged in age-group distribution in each protocol. DUID was most prevalent among males over 30 years of age in D.O.S, while subjects under 30 were clearly prevalent in the SALIVA protocol. The location of SALIVA checkpoints may account for the difference because they were set up near discos, which are mostly attended by young people. Even though significantly more males than females were reported to drive under the influence of alcohol/drugs $[25,26]$, no differences emerged in terms of gender in these two protocols, perhaps because females were more likely to be passengers when they were intoxicated or drugged [27]. In both protocols the majority of drivers $(>60 \%)$ were positive onto the breathalyzer test, and psychoactive drugs were present in over $30 \%$ of suspected cases in both protocols $(33.96 \%$, SALIVA protocol, $34.48 \%$ D.O.S.), in accordance with European data [28]. Thus, actual data showed that a lower percentage of subjects tested positive for drug/alcohol than the police suspected. The reason for this could have been an increased police activity in Perugia to prevent and discourage DUID (a selection bias). Drivers most frequently used cannabis (66.04\% of those positive in SALIVA and 51.72\% in D.O.S), often combined with alcohol and cocaine, as highlighted by the SALIVA protocol. Polydrug abuse is almost a "ritual", especially among young people attending discos. Euphoric substances are taken early in their night out and the effects wear "off" by the end of the night with THC and/or alcohol intake, concurring with other reports [29, 30] and European data [31]. Biechler et al. [32] found that $40 \%$ of drivers who were involved in fatal accidents in France and tested positive to cannabis were also above the legal $\mathrm{BAC}$ limit. There is consistent evidence of a negative dose-related effect of alcohol on driving performance $[33,34]$. Furthermore, THC the active ingredient in marijuana impairs abilities that are crucial for safe driving, causing slow response times and slower driving speeds. It equally impairs cognitive performance, attention maintenance, executive functions and decision-making [29, 35-39]. Drivers who test positive to both alcohol and cannabis have greater probability of making an error than drivers that test positive to only one [30]. Even 
though this synergistic action has been widely described, further research is needed to examine in depth the interactions between cannabis concentrations, alcohol levels and driving performance [30, 31, 37, 40, 41]. Alcohol intake over the legal limit is often associated with a combination of stimulants such as cocaine and amphetamines [35] but neither one of the Perugia protocols reported any data relating to the combined use of alcohol and stimulants. A low rate of opiate intake was, however, detected.

In case of driving under the influence of alcohol, the Italian law specifies in details the modality along with the type of equipment to be used for determining whether the driver was exceeding the admitted intake thresholds.

Penalties for DUID are very strict, and vary depending on the circumstances. The basic sanction is a fine ranging from $€ 1500-€ 6000$, with imprisonment for a term in jail from six months to a year and the additional suspension of the driving license for a year, up to two years. If a collision ensues, the basic sanction is doubled. Namely, sentences foresee a maximum term in prison of eighteen years in case that more than one person is killed. If the driver refuses to undergo toxicological investigations, the applicable sanction includes fines from $€ 1,500$ to $€ 6,000$, a term in prison from 6 months to 1 year and the suspension of the driving license from 6 months to 2 years [23].

Despite the severe consequences of being prosecuted for DUID, the Italian law does not clearly indicate what biological matrix and detection methods are most appropriate to assess the presence of drugs and/or their metabolites in order to establish or confirm DUID. The D.O.S. protocol used oral fluid as a preliminary screening along with urine, followed by blood analysis. Although the drug testing methodology for urinalysis is well established, drugs and drug metabolites are detectable in urine for several days (and sometimes for weeks) after the last intake when they no longer cause psychotropic effects; additionally, the test result is not related to blood levels [42]. Therefore, analyzing the urinary matrix is useless, as it cannot prove that a driver was under the influence of the drug when s/he was stopped. On the other hand, although blood is considered the "gold standard" for drug testing in impaired driving cases, due to its direct connection with the pharmacologic effects of the drug on the central nervous system and current state of impairment [18], collecting blood samples is an invasive procedure that requires escorting the driver to a hospital. This extremely critical phase can take a long time, due to the journey itself and delays in collecting the sample in the emergency department. A recent paper [43] recommended blood sampling "as soon as possible", preferably within $3 \mathrm{hrs}$ since the driver was stopped for a check and the ensuing application of the relevant test protocol, as a longer time interval could reduce the blood concentration to levels below the analytical cut-off, particularly in occasional users [44]. For instance, the concentration of THC, which was the most frequently detected drug in both our protocols, drops fast, reaching values under the reporting limit in a score of minutes [44]. These timing issues could explain why blood analysis did not confirm the relatively higher number $(50 \%)$ of positive samples as the oral fluid screening test. Consequently, only very few drivers $(2.5 \%)$ were sanctioned for DUID under the D.O.S. protocol and \%PPV of saliva screening/blood confirmatory under these conditions is very low $(50 \%)$, as shown in Table 2.

In this regard, we believe that improvements in the timing of blood sampling should be introduced, like sampling blood at the roadside by healthcare professionals or at the closest emergency department using a specific fast-track pathway for individuals who are involved in DUID [43].

The SALIVA protocol used only oral fluid for DUID assessment and the confirmatory test was performed by GC/MS on a second aliquot of the same sample, thus eliminating the waiting time due to transport to hospital. This accounts for the greater effectiveness of the SALIVA protocol over the D.O.S. in DUID assessment. Confirmatory analysis on the same sample that had been collected at road stop confirmed $90 \%$ positivity to the screens, obtaining a higher positive predictive value $(90 \%)$ than the D.O.S protocol (Table 2). Oral fluid is used for DUID in Australian states, Cyprus, and is described in France legislation. In other jurisdictions, positive oral fluid presumptive test results are confirmed with blood tests at hospitals or police stations [45].

Indeed, although oral fluid is a useful matrix for preliminary on-site testing of drugged drivers, some limitations to its use also as a confirmatory 
Table 2. Results for Positive Predictive Values of SALIVA and D.O.S protocol.

\begin{tabular}{|l|c|c|}
\hline & $\begin{array}{c}\text { Saliva screening/saliva } \\
\text { confirmatory tests }\end{array}$ & $\begin{array}{c}\text { Saliva screening/blood } \\
\text { confirmatory tests }\end{array}$ \\
\hline $\begin{array}{l}\text { Collection time of confirmatory } \\
\text { matrix beyond road stops }\end{array}$ & Immediate & With delay \\
\hline True positives & 18 & 10 \\
\hline False positives & 2 & 10 \\
\hline PPT (\%) & 90 & 50 \\
\hline
\end{tabular}

matrix must be considered. Different studies underlined that a reliable correlation of a drug pharmacologic effect can only be based on its blood/serum concentrations as oral fluid concentrations are elevated shortly after drug-use because of contamination of the oral cavity $[11,15,46]$ and the complexity in defining concentration ratio between fluid and blood (OF/B ratio), [18, 46]. The transfer of a drug from blood to oral fluid depends on the compound's physicochemical properties, primarily $\mathrm{pKa}$, protein binding, lipophilicity, molecular weight and spatial configuration $[13,18]$. In oral fluid, ion trapping of basic drugs, such as amphetamine and cocaine, occurs because of $\mathrm{pH}$ differences between blood (7.4) and oral fluid (6.8 at rest). Free uncharged drug is in equilibrium between blood and oral fluid. At the lower $\mathrm{pH}$ in oral fluid, weak bases ionize, thus increasing total oral fluid drug concentrations. Because most narcotic drugs are basic, they are detected in higher concentrations in oral fluid than in plasma [47]. THC is readily detected in oral fluid, but issues have arisen, which have not yet been fully addressed, over distinguishing use from environmental exposure [48]. Although some correlations have been described, large interindividual variations in $\mathrm{THC} \mathrm{OF} / \mathrm{B}$ ratio have been reported, along with a weak relationship between performance impairment and THC oral fluid concentration [18]. Another problem with on-site oral fluid testing is the sensitivity of the devices being used as Musshoff et al. [49] demonstrated that oral fluid devices showed a lack of sensitivity (e.g. for methamphetamine, or benzodiazepines) and specificity (e.g. for THC).

\section{CONCLUSIONS}

A drug finding in oral fluid indicates recent drug use, and may provide a semi-quantitative suggestion of the blood drug concentration for some drugs, which can be useful for screening purposes at roadside [43].
Considering the severe consequences of being prosecuted for DUID in Italy, drugs confirmatory analysis in blood should be cardinal, because blood gives the highest levels of evidence relating to drivers' actual state of impairment. This requirement should be indispensable for a secure conviction of DUID offence in a court. However, from the analysis of the collected data from both protocols and in the light of critical limitations that emerged from D.O.S protocol, that is the lower number of samples that confirmed as positive in the blood analysis, oral fluid collected at the time of the road stop, seems to provide the simplest and more efficient approach to DUID confirmation.

\section{Limits of the study}

The two protocols are hardly comparable both for the different number of drivers asked to pull over for the administration of the protocol-related tests illustrated herewith, and for the different number of individuals suspected of being under the influence of drugs and then subjected to drug screening tests. The major critical aspect emerged is blood sampling in the D.O.S protocol that recorded a time delay which impaired half the samples submitted to confirmatory analysis. We trust, in agreement with other Italian authors $[18,44,50]$, that improvements in the timing of blood sampling as well as integrating procedures should be introduced all over the national territory. Furthermore, if blood samples are collected more than an hour after a driver was stopped, it is advisable to apply a time-related correction factor to infer the drug concentration in their blood when they were asked to pull over, especially when limit values in blood are set by law.

\section{ACKNOWLEDGMENTS}

To all those who have made this study possible, by providing us with access to service and experimental data. 
In particular, we thank:

- The Municipal Police of Perugia and its Director Dr. Nicoletta Caponi;

- The Perugia Section of Traffic Police and its Commander, V.Q.A. Dr. Paolo Di Quattro;

- The Analysis Laboratory of Santa Maria della Misericordia Hospital, Perugia and its Heads of Staff, Dr. Carla Ferri and Dr. Alfredo Villa;

- Dr. George Rettagliata, for his valuable work in the language revision of the paper.

\section{CONFLICT OF INTEREST STATEMENT}

There are no financial or other relations that could lead to a conflict of interest.

\section{REFERENCES}

1. WHO | Road traffic injuries. https://www. who.int/violence_injury_prevention/road_tra ffic/en/.

2. Ojaniemi, K. K., Lintonen, T. P., Impinen, A. O., Lillsunde, P. M. and Ostamo, A. I. 2009, Accid. Anal. Prev., 41, 191.

3. Castillo-Manzano, J. I., Castro-Nuño, M., Fageda, X. and López-Valpuesta, L. 2017 , Transp. Res. Part F Traffic Psychol. Behav., 50,38 .

4. Co-operation Group to Combat Drug Abuse and Illicit Trafficking in Drugs (Pompidou Group). 2004. Road Traffic and Psychoactive Substances: Seminar Organised by the Pompidou Group: Strasbourg, 18-20 June 2003: Proceedings, Council of Europe Pub.

5. Raes, E. and Verstraete, A. G. 2005, J. Anal. Toxicol., 29, 632.

6. Verstraete, A. G. 2004, Ther. Drug Monit., 26, 200.

7. Carfora, A., Campobasso, C. Pietro, Cassandro, P., Petrella, R. and Borriello, R. 2018, Forensic Sci. Int., 288, 291.

8. DuPont, R. L., Voas, R. B., Walsh, J. M., Shea, C., Talpins, S. K. and Neil, M. M. 2012. Traffic Inj. Prev., 13, 31.

9. van der Linden, T., Wille, S. M. R., RamírezFernandez, M., Verstraete, A. G. and Samyn, N. 2015, Forensic Sci. Int., 249, 148.

10. Rohrig, T. P., Moore, C. M., Stephens, K., Cooper, K., Coulter, C., Baird, T., Garnier, M., Miller, S., Tuyay, J., Osawa, K., Chou, J., Nuss, C., Collier, J. and Wittman, K. C 2018, Drug Test. Anal., 10, 663.
11. Samyn, N., Verstraete, A., van Haeren, C. and Kintz, P. 1999, Analysis of Drugs in Saliva. Forensic Sci. Rev., 11, 1.

12. Wille, S. M. R., Raes, E., Lillsunde, P., Gunnar, T., Laloup, M., Samyn, N., Christophersen, A. S., Moeller, M. R., Hammer, K. P. and Verstraete, A. G. 2009, Ther. Drug Monit., 31,511 .

13. Gjerde, H., Mordal, J., Christophersen, A. S., Bramness, J. G. and Mørland, J. 2010, J. Anal. Toxicol., 34, 204.

14. Crouch, D. J., Walsh, J. M., Cangianelli, L. and Quintela, O. 2008, Ther. Drug Monit., 30, 188 .

15. Cone, E. J. 1993, Ann. NY Acad. Sci., 694, 91.

16. Menkes, D. B., Howard, R. C., Spears, G. F. and Cairns, E. R. 1991, Psychopharmacology (Berl)., 103, 277.

17. Bakke, E., Høiseth, G., Arnestad, M. and Gjerde, H. 2019, J. Anal. Toxicol., 43, 228.

18. Busardo, F. P., Pichini, S., Pellegrini, M., Montana, A., Lo Faro, A. F., Zaami, S. and Graziano, S. 2017, Curr. Neuropharmacol., 16,84 .

19. Fiorentin, T. R., Scherer, J. N., Marcelo, M. C. A., Sousa, T. R. V., Pechansky, F., Ferrão, M. F. and Limberger, R. P. 2018, J. Anal. Toxicol., 42, 69.

20. Christophersen, A. S., Mørland, J., Stewart, K. and Gjerde, H. 2016, Forensic Sci. Rev., 28, 37.

21. Jamt, R. E. G., Gjerde, H., Normann, P. T. and Bogstrand, S. T. 2017, Traffic Inj. Prev., 18,681 .

22. Ministero delle Infrastrutture e dei Traporti. Legislative Decree n. 285, 1992. http:/www.mit.gov.it/mit/site.php?p=norma tiva\&o $=$ vd\&id $=1 \&$ id_cat $=\& i d \_$dett $=0$

23. Road Traffic Law n. 41, 2016 (RTL 41/2016). Gazzetta Ufficiale. https:/www. gazzettaufficiale.it/eli/id/2016/03/24/16G00 048/sg.

24. Gruppo Tossicologi Forensi Italiani. Linee Guida per Strutture dotate di Laboratori per gli accertamenti di Sostanze d'Abuso con Finalità Tossicologico-Forensi e MedicoLegali. http://www.gtfi.it/wp-content/ uploads/ 2017/06/LG_biologico.

25. Harré, N., Field, J. and Kirkwood, B. 1996, J. Safety Res., 27, 163. 
26. Salomone, A., Pirro, V., Lombardo, T., Di Corcia, D., Pellegrino, S. and Vincenti, M. 2015, Drug Test. Anal., 7, 407.

27. Lipari, R. N., Hughes, A. and Bose, J. 2013, TheCBHSD Report: Center for Behavioral Health Statistics and Quality, Substance Abuse and Mental Health Services Administration. Rockville, MD.

28. European Monitoring Centre for Drugs and Drug Addiction (EMCDDA). 2012, UID Project, 1-58.

29. Ramaekers, J. G., Berghaus, G., van Laar, M. and Drummer, O. H. 2004, Drug Alcohol Depend., 73, 109.

30. Dubois, S., Mullen, N., Weaver, B. and Bédard, M. 2015, Forensic Sci. Int., 248, 94.

31. Jones, A. W., Holmgren, A. and Kugelberg, F. C. 2008, Addiction, 103, 452.

32. Biecheler, M.-B., Peytavin, J.-F., Facy, F. and Martineau, H. 2008, Traffic Inj. Prev., 9, 11.

33. Kelly, E., Darke, S. and Ross, J. 2004, Drug Alcohol Rev., 23, 319.

34. Penning, R., Veldstra, J. L., Daamen, A. P., Olivier, B. and Verster, J. C. 2010, Curr. Drug Abuse Rev., 3, 23.

35. Mura, P., Chatelain, C., Dumestre, V., Gaulier, J. M., Ghysel, M. H., Lacroix, C., Kergueris, M. F., Lhermitte, M., Moulsma, M., Pépin, G., Vincent, F. and Kintz, P. 2006, Forensic Sci. Int., 160, 168.

36. Ramaekers, J. G., Kauert, G., van Ruitenbeek, P., Theunissen, E. L., Schneider, E. and Moeller, M. R. 2006, Neuropsychopharmacology, 31, 2296.

37. Ronen, A., Gershon, P., Drobiner, H., Rabinovich, A., Bar-Hamburger, R.,
Mechoulam, R., Cassuto, Y. and Shinar, D. 2008, Accid. Anal. Prev., 40, 926.

38. Ramaekers, J. G. 2018, JAMA, 319, 1433.

39. Micallef, J., Dupouey, J., Jouve, E., Truillet, R., Lacarelle, B., Taillard, J., Daurat, A., Authié, C., Blin, O., Rascol, O., Philip, P. and Mestre, D. 2018, Fundam. Clin. Pharmacol., 32, 558.

40. Bramness, J. G., Khiabani, H. Z. and Mørland, J. 2010, Addiction, 105, 1080.

41. Lamers, C. T. J. and Ramaekers, J. G. 2001, Hum. Psychopharmacol., 16, 393.

42. Musshoff, F. and Madea, B. 2006, Ther. Drug Monit., 28, 155.

43. Busardò, F. P., Pichini, S. and Pacifici, R. 2017, Clin. Chem., 63, 781.

44. Ferrari, D., Manca, M., Premaschi, S., Banfi, G. and Locatelli, M. 2018, Forensic Sci. Int., 288, 211.

45. European Monitoring Centre for Drugs and Drug Addiction (EMCDDA). 2018, Available from: http://emcdda.europa.eu/publication/ insights/2014/drugs-and-driving_en.

46. Langel, K., Gjerde, H., Favretto, D., Lillsunde, P., Øiestad, E. L., Ferrara, S. D. and Verstraete, A. G. 2013, Drug Test. Anal., 6 , 461.

47. van der Linden, T., Legrand, S.-A., Silverans, P. and Verstraete, A. G. 2012, J. Anal. Toxicol., 36, 418.

48. Huestis, M. A., Verstraete, A., Kwong, T. C., Morland, J., Vincent, M. J. and de la Torre, R. 2011, Clin. Chem., 57, 805.

49. Musshoff, F., Hokamp, E. G., Bott, U. and Madea, B. 2014, Forensic Sci. Int., 238, 120.

50. Favretto, D., Visentin, S., Stocchero, G., Vogliardi, S., Snenghi, R. and Montisci, M. 2018, Traffic Inj. Prev., 9, 786. 